\title{
PSYCHE.
}

\section{A COMPARISON OF COLIAS HECLA WITH C. MEADII AND \\ C. ELIS.}

By thomas E. BeAN, I.Aggan, alberta province, CANAdA.

[Annual address of the retiring president of the Cambridge Entomological Club, 8 March, I895.]

The Males.

As the males of Meadii and Elis are but narrowly separate, I have made a series of measurements from which to derive numerical averages in the two species, as to total expanse of the front pair of wings, as to breadth of dark border of primary at middle of outer margin, and particularly as to the proportion between this breadth of dark border and the expanse of the corresponding wing. These tests were also applied to Hecla, although there scarcely of equal significance on account of the small number of examples at my command. Mr. David Bruce very kindly sent me a large series of Meadii for examination, so that I have been enabled to compare $42 \delta, 239$ Meadii with $78,5 \%$ Hecla and $5^{6} \delta, 75 \%$ Elis. The males were individually measured, and the data reduced to general averages, with following results.

Average total expanse (sum of the length of the two primaries plus breadth of body): Meadii, nearly $47 \mathrm{~mm}$; Hecla, nearly $45 \mathrm{~mm}$.; Elis, nearly $50 \mathrm{~mm}$.
Average breadth of dark border of primary, at middle of outer margin: Meadii, $4 \frac{1}{4} \mathrm{~mm}$.; Hecla, $2 \frac{5}{7} \mathrm{~mm}$.; Elis, $3 \frac{2}{7} \mathrm{~mm}$.

Proportion between average breadth of dark border of primary and average length of primary (measured from apex to center of base of wing): in Meadii the breadth of dark border proved to be slightly over $19 \frac{1}{3}$ per cent of length of primary, in Hecla 13 per cent, in Elis slightly over 44 per cent.

These are significant averages. The individual measurements from which they were obtained show that in regard to expanse of wing, as in other respects, Meadii is in considerable degree less subject to variation than Elis. Meadii, in its extreme terms of expanse, only varies to $4 \mathrm{~mm}$. below its average figure and to $3 \mathrm{~mm}$. above its average. Elis ranges to ro $\mathrm{mm}$. below and to $6 \mathrm{~mm}$. above its own average term. The extremes in Meadii are only $7 \mathrm{~mm}$. apart, but in Hlecla they are $10 \mathrm{~mm}$. apart, and Elis has a range of $16 \mathrm{~mm}$. of variation in this dimension, or I I $\mathrm{mm}$. if one extremely abnormal example be omitted from the comparison. The uniformity of expanse in 
Meadii is remarkable. Omitting two examples, the largest $(50 \mathrm{~mm}$.) and the smallest $(43 \mathrm{~mm}$.), the remaining forty show a variation in expanse of only $4 \mathrm{~mm}$., from 45 to $49 \mathrm{~mm}$. In Elis, leaving out the lowest term (one specimen of $40 \mathrm{~mm}$.) and the highest term (two of $56 \mathrm{~mm}$.), the pendulum of variation still swings between 45 and $54 \mathrm{~mm}$., a range more than double that of Meadii. Hecla, also, is evidently far more variable in expanse than Meadii, as shown even by this small series.

A comparison of the shape of dark border of fore-wing furnishes a valid distinction, parting Hecla from Elis and even more emphatically from Meadii, while it separates less decisively Elis from Meadii. In a very large majority of the Meadii, the dark border of fore-wing extends a considerable projection toward base of wing, both at internal angle and at apex. Owing to this salient projection the fore-wing is rendered extremely broad on costa. The curvature of inner edge of border, however, is so great that the costal excess of breadth is rapidly parted with in the backward course of the border. From a point of fore-wing nearly opposite the cell-spot, to a point a little back of posterior median nervule, the dark border of Meadii $\delta$ in a large majority of the specimens examined maintains closely an equal breadth. This is plainly the case in 39 of the 42 . In the other 3 the border narrows very slightly from the front to the back of this median part; in one of them on both fore wings, in the other two on right wing only. The rule then in Meadii, and a rule of almost universal application, is that the dark border of fore-wing is disproportionately broad on costa, loses this excess of breadth anterior to a point nearly opposite the discal spot, and throughout the median portion of the wing maintains closely an equal breadth. In a considerable proportion of individuals the border abruptly narrows more or less a little anterior to the submedian nerve, the disk color encroaching upon the marginal border in a broad irregular sinus whose deepest extension usually occurs at the submedian nerve.

The seven males of Hecla present a radically differing pattern of fore-wing border from that displayed by Meadii. The excess of breadth at costa, instead of being quickly dissipated in the backward progress of the border (as in Meadii), is parted with very gradually and evenly, so that Hecla's dark border becomes progressively narrower from costa to internal angle. This general method is plain in all the seven, though in two of them a part of the median extent of the border shows but a slight narrowing within itself. In all the seven a gradual reduction of breadth from costa to internal angle is a systematic detail, and it would effectively part them from all these Meadii males were there no other distinction. The differing shape of the fore-wing dark border is a far more decisive distinction between the two species than is the difference merely in breadth of border. 
Hecla in these specimens differs from Meadii by exhibiting less tendency to extension of the dark border inward at costa and at internal angle : in Meadii, the color-pattern is salient and aggressive ; in Hecla, stationary or retrograde.

The color on veins crossing dark border of primary seems to be a fluctuating and indecisive character. A tendency to show yellow scales on the veins of anterior part of border is somewhat prevalent in Meadii, while in Hecla more commonly than in Meadii the posterior part of wing also exhibits yellow veining on the border. The present material indicates that when the yellow veining occurs in Hecla it will generally be somewhat uniformly presented throughout the border, but in Meadii usually predominant toward apex.

The male of Elis approaches that of Meadii so closely that individuals of the former can be found which scarcely seem to differ tangibly from the latter: by a vague contrast in general appearance they part from Meadii and identify themselves with Elis. This somewhat elusive difference between closely similar individuals of contiguous species is difficult of analysis. Adjoining species are most readily discriminated as unities, by the opposition or unlikeness of the entire systems or combinations of pattern, containing in part closely similar or identical elements, and in part alien elements. A large series of each tends to manifest the entire amount of alienation separating each species from its nearest allies. Single individuals are at best imperfectly representative; being themselves specialized fragments, they merely represent what the species would be if similarly specialized throughout. In estimating the relation between adjacent species adequate series should be examined. Safe conclusions cannot be drawn from comparison of isolated examples until the representative value of those examples has been ascertained. Individuals are typical or divergent: in the latter case, if divergent in the direction of the proximate species they express in relation to that species less than a typical amount of alienation; if divergent in a direction leading away from the proximate species, they exhibit relatively to it a degree of alienation (biological estrangement) which is greater than the typical contrast. From this it follows that individuals which have a more than typical degree of divergence from each other, representing adjacent species, will over-contrast those species, and on the other hand, unusually approximate examples in contiguous species will under-contrast the two species. In species so near of kin as Elis and Meadii, the most closely resemblant examples are exactly those which are least representative of the characters peculiar to their respective species, and most highly representative of characters common to the several closely allied species. Elis being greatly more variable than Meadii, the closest approximation between them is on the part of exceptional males of Elis. It may be said that Meadii as 
a species is very close to certain exceptional males of Elis, and conversely that some Elis males are very near to the species Meadii. The approximation is on the part of occasional conservatively divergent Elis males. These divergent individuals of Elis, when isolated from their fellows and brought into comparison with Meadii, seem closer to the latter than they really are : the cause of this is, that the resemblance to Meadii is made conspicuous on account of the attention being attracted to it by the presence of examples of Meadii, the greater resemblance to the species Elis being overlooked by lack of a proper representation of Elis for comparison.

\section{The Females.}

In these three species the females compare very differently from the males. Elis and Meadii, which sometimes approach closely in the male, manifest in the female only a moderate general affinity, offset by a striking antagonism of patterh rarely found between such close allies in this genus. Hecla and Meadii, however, whose males differ widely, are parted in the female sex chiefly by fluctuating averages, so that their contrast in that sex is comparatively vague and informal, and in occasional individuals is found resemblance to the allied species in a degree which has sometimes proved confusing.

In the border of primary in Meadii the yellow spots are ordinarily irregular in the extreme in size and outline; and they are sometimes hazy or nebulous, and extremely pallid, - two such examples are in this series. The variance between individuals as to degree of development of the yellow spots is great. There is a decided tendency to total eclipse of the spots, a tendency so influential that in seven specimens of this small lot the border is almost entirely solid black. This species exhibits great eccentricity in the presentation of the maculae, which are frequently of irregular shapes, often indeed peculiarly erratic in outline. It is the far rarer instances, with tolerably neat and comparatively even-sized spots, which closely resemble some Hecla; but such Meadii are not at all representative examples. The eccentricity of maculation spoken of is foreign to the method of Elis, and it is a peculiarity of which my small series of Hecla contains no suggestion. In the maculation of Hecla, as compared with that of Meadii, the spots are more equal in the same individual, and more uniform, taking one example with another.

In both Meadii and Hecla the yellow spots on dark border of primary are unequally developed, the mid-wing spot heing often obsolete, and almost invariably at least feeble in develop. ment. This is the established method in both species.

Elis is remarkable for its symmetry of pattern, the maculation being in general conspicuously harmonic in the individual, and the middle spot having 
approximate equality with the others. Examples of Elis in which the border spots of primary are not pretty uniform in size and shape, and those in which the mid-wing spot is not at least moderately well developed, are exceptional. The most informal in this series of Elis have the spots more neatly regular than in the most formal Meadii in the lot. Those Meadii with the spots largest are not nearer to Elis on that account, but rather show stronger contrast, as the diverse system of maculation in the two species is thereby rendered more obvious.

An occasional Meadii, having the spots on primary border more symmetrical than is usual, closely resembles some Hecla, so that in a large series of both a small percentage of the Meadii might prove difficult to part from a few of the Hecla by this test solely. In a large majority of cases, however, the two females differ widely in character of dark border of hind-wing; 18 out of 23 of these Meadii have a practically solid black hind-wing border, and 3 of these 5 Hecla have a most distinctly maculated border with the yellow spots large and conspicuous. Meadii with hind-wing border partly maculated, and Hecla with maculation of hind-wing border partly obscured, might not readily separate on this character alone. It follows then, that among the small number not distinguishable by characters of fore-wing border, one individual in many may also fall in the small proportion with hind-wing border of ambiguous char- acter : that is to say, a percentage of a percentage occurs wherein the maculation of dark border of both primary and secondary is liable to prove too approximate or too obscure to rely upon in determining the position of the individual. Even these rare instances of close approximation should not defeat a student familiar with the two species. Other specialties of pattern are in some degree indicative, and it rarely indeed occurs that all significant distinctions lapse in a single individual. There remains also that indefinite but obvious fact known as "the general appearance," which furnishes an experienced observer with the most reliable and satisfactory guide in distinguishing one species from another.

In a general view of the three species, the most obvious fact is that Hecla male is distinct from the respective males of Meadii and Elis. Also, properly representative material makes conspicuously evident the divergence of the female of Elis from the females of Hecla and Meadii. The close approximation occurs between Hecla and Meadii in the female, between Elis and Meadii in the male. This complex of relationship is perhaps partly capable of explanation. Hecla may safely be considered the oldest of the three species, and Elis the youngest. In Colias the law of the agency of sex in race progress appears to be that the male is the conservative and the female the progressive sex. Accordingly, in the alliance under consideration, Hecla being the oldest 
species, its male should be the most conservative element in the alliance; and Elis being the youngest species, its female should prove to be the most progressive element. Hecla male and Elis female occupy outposts as to race progress, and are thus of necessity more completely differentiated than the other elements of the alliance.

The comparison so far is from notes made several years ago. Having lately re-examined all descriptions and figures of Hecla available to me here in the wilderness, I am inclined to think my analysis of the figure-pattern accurate. In order to amplify my knowledge of Hecla, I applied to Dr. Strecker for details in regard to the Hecla males in his collection, making very specific enquiry as to shape of dark border of primary. In response three pen sketches were sent me, representing the range of variation observed in the Lapland and Greenland examples. 'These drawings show a method of border corresponding to that found in my own series and described in the present analysis. Another sketch represented the border of primary of Meadii, delineating precisely the style of dark border I have described as practically the constant fashion in that species.

In print, as also in correspondence, Mr. W. H. Edwards refers to the general ground color of some Meadii as indistinguishable from that of Hecla, or of some Hecla, and hales this resemblance into court as a witness to prove Meadii and Hecla one species. Hecla was already well known when $\mathrm{Mr}$. Edwards named Meadii, and if there is now no valid distinction between Meadii and Hecla there was none then, and in that case Meadii should not have been described. In Butterflies N. A., Ist series, Mr. Edwards closes thus his Meadii text: "This Colias bears close resemblance to Hecla, but may be readily distinguished by the glandular spot before spoken of (see Plate), a character not found in Hecla, and so decisive that it is not necessary to point out minor points of difference." At this late day Mr. Edwards seems to find but one item of difference between the two species, the "glandular spot" - and it is as evident an embarrassment to him at present as it was convenient formerly. Probably it is not unfair to say that Meadii when named was concluded distinct from Hecla simply on account of two circumstances: one being the presence of the "glandular spot," the other the fact that the original catch of Meadii consisted of specimens colored a redder orange than Hecla ordinarily displays. Mr. Edwards is open to criticism in both his earlier and later attitudes in regard to Meadii. Considering Meadii distinct from Hecla because the original material of Meadii was of a redder orange than that customary in Hecla was the initial error. The acceptance of this color fact as a proof of distinctness was incorrect in two ways: first, because dependent on the violent assumption that all other Meadii would prove of as red an orange 
as those first under view, - an assumption contrary to analogy; second, as involving the assumption that a degree of redness is a definitive character. Color difference, particularly a mere difference in degree of the same color, though a valuable descriptive character, is in Colias far from definitive or demonstrative. It is a character which itself requires examination before it can serve as an interpreter. Used blindly it may divide one species as readily as it separates two. After discovery of the fact that two species present, as to ground color, a difference which although not universal is general and consistent, this color difference becomes a valid descriptive character in contrasting the two as species, but it cannot be used definitively. Nor is it necessarily effective in assorting individuals. Individuals usually do not represent the species as to every detail of the species' character. It is indeed probably true that an individual need not represent in obvious degree any element or quality peculiar to the species. Its participation in the species' character may be limited to biological identity. But as previously suggested, for all the significant characters to lapse in one individual must be an extremely rare incident. Latterly, Mr. Edwards has lost confidence in Meadii. Having in the first instance adopted it as a good species partly on the merits of a considerable catch of well-behaved examples conspicuously redder than Hecla, he lately inclines to consider Meadii identical with Heila because some few admittedly exceptional examples have been found which are not of a redder orange than that Hecla wears in its northern summer resorts. The later opinion rests upon an assumption as untenable as that involved in the earlier view. If Meadii and Hecla could be shown to be absoluteiy lacking in color-difference as species, - that is to say, if in like conditions like color effects invariably resulted, - it would not prove the two identical, but would merely show the stated color effect to be without value as a means of distinguishing the two species. As an undeniable matter of fact, the ground color in the species Meadi $i$ is not the same as in the species Hecla, but the difference occurs as a general chromatic average, applying to Meadii as a species, under usual conditions, and not necessarily effective in individuals subjected to exceptional environments. If all Meadii were Hecla-colored, or if all Heclas were of the degree of redness customary in Meadii, the loss of the chromatic contrast would render the two species less readily distinguishiable. But the permanent elements of figure-pattern, which have resulted from the long continued biological estrangement of the two species, and which are reliable evidences of the species' diversity, are efficient not only to define but also to distinguish the two species. The scientific comparison between Meadii and Hecla as to color does not consist in bringing two or three exceptionally pale Meadii into direct contrast with a 
lot of Heclas; and it is not a legitimate conclusion that because one or two Meadii in a hundred are of about the same shade of orange usual in Hecla, therefore Merdii and Hecla constitute one species. Comparing Meadii as a species with Hecla as a species we find, as might be expected, the color difference not a definite character. But we also find that the two species show very different averages as to color, and that it is descriptively accurate to call Meadii a red-orange species, and Hecla a pale-orange species. That one is in general a red species, and the other a paler species, is no proof that they are distinct. Equally, the fact that some Meadii are not so red as others does not prove that all Meadii are Hecla, nor even that some Meadii are Hecla.

In Meadii male the basal patch of erected and densely crowded scales near costa above secondary wing, the "gland," the "mealy spot," etc. is well developed. It is moderately variable in shape and size. In color it varies from pallid yellow (nearly white) to orange, and is often partially tinged with red. Hecla lacks this peculiar cluster of metamorphosed scales, and its absence proves a difficult fact alike to those who incline to consider Elis nearer to Hecla than to Meadii, and to those who do not perceive any other distinction between Hecla and Meadii. Elis presents this structure about as in Meadii, as to form, size, and color. One Elis male partly approaching Christina in general markings has the scale-patch especially feeble, not nearly of the usual size and definiteness : this specimen is decidedly abnormal in appearance, and it is almost the only Colias example I have seen with characters suggestive of hybrid origin. From correspondents I learn that of late diligent search has been made for specimens of Hecla male endowed with the cluster of modified scales. This is expecting too much of Hecla. Being the older form, and having long lived under the present restrictive conditions, it is not likely to develop progressive variations. More plausible would be a search for occasional retrogressive variations in Meadii or Elis affecting this structure. Premising the descent of Meadii from the earlier stock resem. bling Hecla, we may infer that the initial development of this peculiar scale structure occurred as an early incident in the differentiation of the new species. Should an occasional Meadii or Elis occur lacking this structure such finds would be of great interest as indicating the present degree of mobility of the species' character. But occurrences like those would not be of the slightest force as proving Hecla and Meadii identical. Quite the reverse, for the extreme infrequency of the exceptions would emphasize the relative universality of the normal tendency. No examples of Elis or Meadii males lacking this structure have as yet been detected. Meadii, being exceedingly stable in its averages, is probably no longer subject to so decisive a reversion. Should a reversionary Meadii be found with this 
character lacking, we may most reasonably interpret the incident on its merits, and not in the manner of the people who seek after a sign. The occurrence will simply be an extremely unusual fact, contrasting with an almost universal occurrence of the directly contrary fact.

Colias has few species for so dominant a genus, a wide range of variation being retained within the limits of a species. Consequently, species which are closely allied contrast very unequally in dissimilar comparisons, a great or a small contrast resulting according as typical or approximate specimens are compared. Hence it is, the species differ somewhat vaguely, so that superficial students are easily convinced that we have far too many species of Colias. The general unity of pattern-method throughout the genus, combined with the wide species-content as to variation, causes a profuse diversity within the species, accompanied sometimes by an almost bewildering resemblance between one species and another. Even species not adjoining may show an approximation sufficient to render difficult an estimate of their degree of alliance. In the case under consideration this applies. It appears to me somewhat probable that the approximation between Hecla and Meadii may be merely an extreme instance of what for want of a better term I will call diffusive resemblance, and not in reality a result of contiguous alliance. Until the larva of Hecla is known we cannot be quite certain of the degree of relationship existing between Hecla and its two Rocky Mountain allies. It is easily known to be a different species from the other two. The view that the three species are directly related, although highly plausible on geographical grounds, is preliminary rather than final. It is not especially improbable that the closer alliance of Hecla is with Chrysotheme and Thisoa. The larva of Elis is greatly similar to that of the untypical form of Colias nastes which occurs in the Bow Valley above timber. The distinction between them is that Nastes is smaller, darker, and apparently far more primitive than Elis. The imagos indicate still more plainly the linear gap between the two species. The larva of Hecla is a desideratum, to assist in determining whether that species is more closely allied to Chrysotheme or is one of the intermediate terms between the early stock of Nastes and the modern forms Meadii and Elis.

In Proceedings of the Acad. of Nat. Sciences of Philadelphia, page ${ }_{156}$, 1892, Dr. Skinner describes "Colias hecla pallida N. var. $\$$," from a single instance, and a figure of this example is published in Entomological News, Vol. 3, plate 2. Both the description and the figure suggest Nastes rather than Hecla. The figure indeed admirably represents the form of Nastes female which is found on the mountains about Laggan, larger than the Labrador type, and nearer to the form Werdandi of northern Europe. I make this note hoping it 
may cause Dr Skinner to compare his example with Nastes of the Rocky Mts. Nastes at Laggan is an exceedingly variable species, and the published figure of Pallida inclines me to think the original may be a somewhat untypical $\&$ Nastes, instead of a Hecla. Analogy in Meadii and Elis does not favor the probability of a white $q$ in Hecla.

Since my earlier account of Colias Elis, in the Canadian Entomologist, July I 890 , little further knowledge of its geographical distribution has been obtained. Mr. H. H. Lyman found one $q$ at Banff, 36 miles east of Laggan, in $\mathrm{IS} 9 \mathrm{O}$, and $\mathrm{Mr}$. H. K. Burrison collected several specimens there in the same season. I am not aware of any other observations outside the original district extending from Laggan to Hector. Meadii, as distinct from Elis, does not occur at Laggan, and there is no separation of Elis into two forms, one of them more closely approaching Meadii. The publication of Meadii by Capt. Geddes as occurring in Kicking Horse Pass is probably to be understood as cancelled by his later announcement of Elis from the same locality. Up to the present time Meadii seems not to have been found north of the international boundary, and Hecla has, I think, not yet been reported from points nearer this district than Hudson's Bay and Alaska. Elis thus retains its vague geographical isolation.

I am now able to speak definitely in regard to the supposed "albino $q$ " of
Elis. Mr. Strecker's determination proves to have been based upon several + examples of a Laggan butterfly closely allied to Pelidne, which I have in correspondence designated by the MS. name Colias minisni, $\rightarrow$ of which perhaps further hereafter. Having sent Mr. Strecker fine examples of this pale female Colias, and also of its appropriate male, he distinctly recognizes the $q$ as the original of his Elis albino $q$, and the latter determination is to be considered recalled.

My series of Elis now represents the result of eight seasons' collecting. During that time every specimen collected has been critically examined, and every example requisite for an understanding of the species has been embodied in my collection. The representation is now so complete that probably no element of the variation is lacking, and the species stands confessed in all its multiform simplicity. I find that in proportion as the material becomes more fully representative so the individuality of Elis as a distinct species grows, with the effect that occasional instances partly shading toward Meadii have become at length more evidently absorbed into Elis by the presence of intermediate steps of variation which unite the extremes with the more typical elements of the species. Complete material supplies a fuller presentation of the consecutive variation, and results in a more accurate identification and explanation of the imperfectly typical examples. This 
perfected series of Elis does not appear to bring the species as a whole nearer to Meadii, but has rather a contrary effect. While it renders increasingly plain the fact that the neutral ground between Meadii and Elis is but narrow, measured for instance by the relative unlikeness of any two closely approximate males in the two species, yet it makes more appreciable than before the systematic alienation, and the consequent diversity of averages, distinguishing the two closely allied kinds. Species so closely related as these cannot be satisfactorily estimated from scrutiny of a few isolated examples. In critical cases, before a doubtful specimen can aid in a final determination of the limits and position of the species, the dubious example must itself be identified by comparison with the species. If two males of Elis, one highly typical and one extremely divergent in the conservative direction, are brought into contrast with the adjacent species Meadii, the very obvious hiatus between the two Elis (resulting from absence of perhaps a dozen usual intergrades) may impress an observer as a far more momentous separation than the narrow interval parting the off-type individual of $E l_{i}$ is from the species Meadii. But when the missing intergrades are procured, and the vacuum (which Nature abhors) is filled, the resemblance of the untypical example to Meadii at once takes secondary place, and its affinity for the species Elis becomes the prominent fact.

\section{WESTERN PEDICIAE, BITTACOMORPHAE AND TRICHOCERAE.}

By C. R. OSTEN SACKEN, HEIDELBERG, GERMANY.

The perusal of J. M. Aldrich's paper in Psyche, February 1895, aroused my recollections of twenty years ago, and made me examine old manuscript notes of mine. What I found in them may be of some use in connection with the three above-named genera.

Pedicia obtusa. Since I described this species in 1877 , I have received from Mr. James Behrens of San Francisco a pair of it, taken in Siskiyou Co., Cal., on Sept. 27 and Oct. 6. Both specimens agree with the one described by me in not having the brown pattern of the wings prolonged towards the posterior margin. The female has the usual double stripe in the middle of the thorax of a saturate yellow, longitudinally bisected by a brown line, which is the prolongation of the narrow median black line of the pronotum (or collar), and reaches backwards the tip of the scutellum. The male is a somewhat immature specimen, paler yellow in coloring; the thoracic brown line is perceptible 

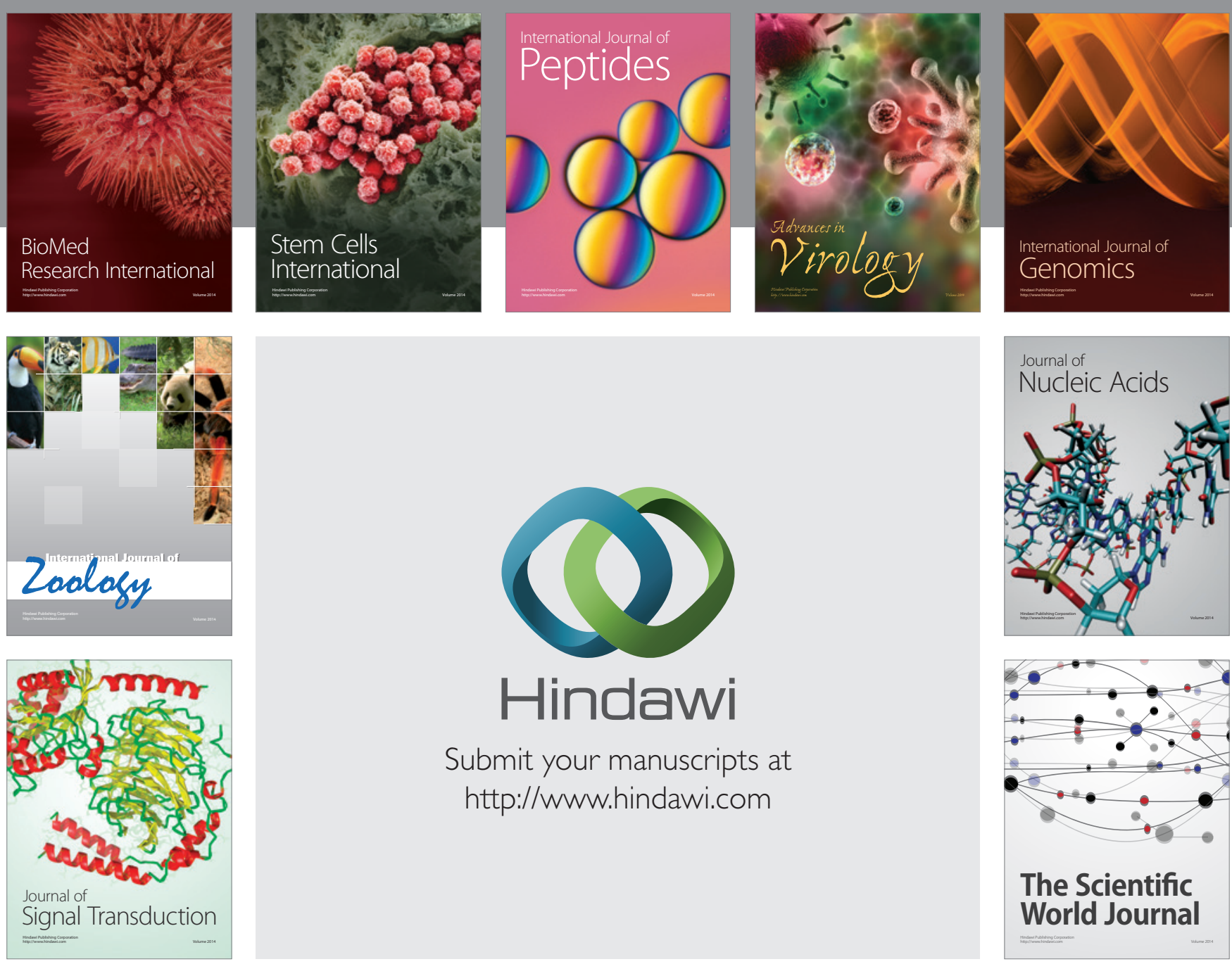

Submit your manuscripts at

http://www.hindawi.com
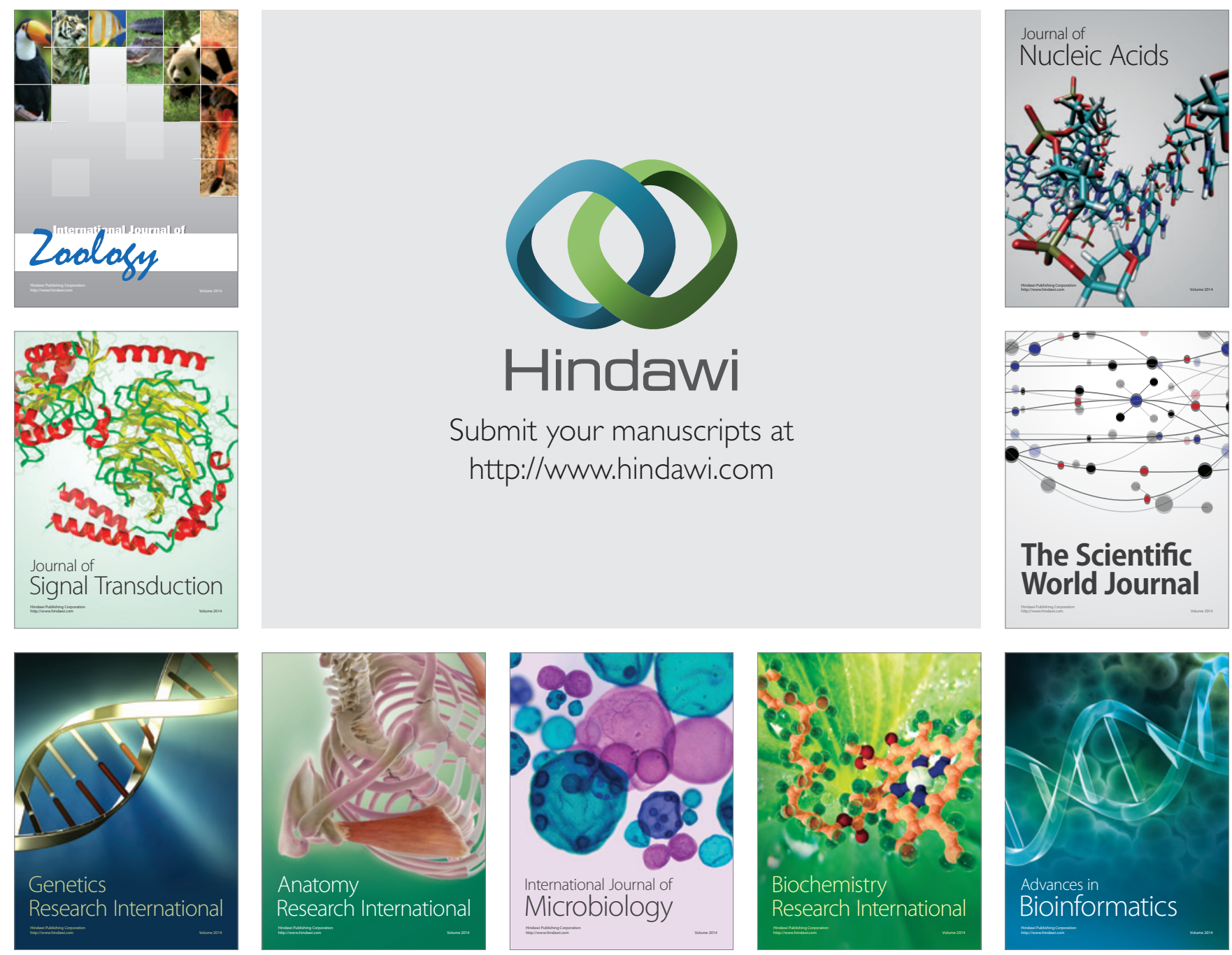

The Scientific World Journal
